\title{
ReCa: A Social Relationship Mining Tool in Virtual Learning Environment
}

\author{
http://dx.doi.org/10.3991/ijet.v8i3.2686 \\ Niki Yuquing Guo \\ Zhejiang University, Hangzhou, Zhejiang Province, P. R. China
}

\begin{abstract}
This paper provides an introduction to a members' Relationship Calculation Tool (ReCa) of Sakai platform and a brief discussion of its design research process. Learning Management Systems (LMSs) usually gather a range of users' performance log, which can be used in educational data mining in different perspectives, including social relationship exploration. However, data mining approach usually consumes a lot of manual work and requires database search skills. There is still no effective tool for instructors to find out participants' social relationship in online learning community. The main objective of ReCa design is to fill the gap by easily carrying out participants' social relationship matrix in Sakai platform.
\end{abstract}

Index Terms-Educational data mining; Sakai; social relationship

\section{INTRODUCTION}

During the first decade of the 21 st Century, the use of e-learning has increased rapidly around the world. ICT enriched teaching and learning experiences, and Learning Management Systems (LMSs) have been widely used by learners and lecturers. Some examples of commercial systems are WebCT, Blackboard and TopClass, while some examples of Free/Open systems are Sakai, Moodle, and Caroline. Open LMSs enables the creation of powerful, flexible and engaging online courses and experiences [1]. At present, Moodle is one of the commonly used LMS in primary-and-middle school. Meanwhile, Sakai is more popular in higher education institutions (HEIs).

Based on different learning and instructional theories, plenty of flexible teaching frameworks have been offered to technology-based learning, including self-paced learning, instructor-led learning, peer-to-peer interaction learning and blended learning. Different types of courses have different levels of interaction. For example, education game system and video-conference system have higher level of students-to-students interaction and students-toinstructor interaction, while self-paced learning has lower level of interaction and communication between students. Supported by the seminal works of theorists [2]-[4], socioconstructivist pedagogies emphasize learner-centered instructional design and recognition of the social nature of learning that calls for dynamic learner interaction in learning community [4]-[5].

In measuring online interaction, one technique frequently used is Social Network Analysis (SNA). Educators can improve online instructional design by understanding the social nature of the course. Unfortunately, there is no LMS provide the tool to find social relationship between students-teachers, students-students and students- resources. This paper aim to introduce a tool for mining members' relationship in online learning community based on Sakai platform. By using this tool, educators can understand social nature easily and quickly without having data mining knowledge and database skills.

\section{LITERATURE REVIEW}

\section{A. Learning Community}

Rovai [7] once declared that, in a classroom where learners have close relationship, they could feel connected, trust and help others, they could actively engage in two-way communications, which would reduce social and psychological distance among people, and they could also share common interests, values and learning objectives. According to Wenger [8], community of practices was defined as groups of people who share a concern, a set of problems, or a passion about a topic, and who deepen their knowledge and expertise in this area by interacting on an ongoing basis. Describing Community of Practice theory, Wenger asserted that there are three key elements that associate practices with community: joint enterprise, mutual engagement and shared repertories. Collaboration among members is necessary to effectively cultivate a thriving online learning community [9]-[10].

Learning community is an essential part of successful online education [11]. However, in a typical online learning environment, members are usually separated from each other by time and space. Lack of closer relationship brings about feelings of isolation, which can lead to dissatisfaction, low sense of community and poor performance [12]-[13]. Rovai [14] also argued that encouraging a sense of community will effect student satisfaction, learning and retention. Because of the growing recognition of the importance of social construction, how to promote learning communities has therefore become a common goal among educators in their attempt to facilitate student learning [16]. Analyzing the social nature and finding the factors that could promote or hinder social collaborative actions in online learning environment is an important part of the present research work and hopefully the results of the study can facilitate learners working together to negotiate meaning and improve learning achievements.

\section{B. SNA}

SNA focuses on patterns of relationships among actors and it examines the availability of resources and the exchange of resources between these actors [17]-[19]. The resources exchanges in a learning community can be of many types, including information, learning resources, social support, or influence. The focus on patterns of relationships, such as who works with whom or who ex- 
changes information with whom, distinguished social network analysis form other analysis technique [20]. A relationship is a specific kind of interaction among learners, for instance, learning resources sharing relationship. Researchers gather these relationship data to help educators improve learning environment or instruction design to promote online interaction and facilitate the sharing of knowledge.

Data can be typically gathered through questionnaires or interviews. Researchers may ask such questions as: "who do you did homework with?", "who do you go to for advice?" Researchers can also go to forum and observe relationship between learners to elicit the quality and content of the network ties, and create spreadsheets that shows which participants responded to each other's and the facilitator's posts and how often they did so. It usually consumes a lot of manual work or requires database search skills. There is still no effective tool for instructors to find out participants' social relationship in online learning community. This research tries to build a social relationship mining tool that can fill the gap by easily carrying out participants' social relationship matrix in Sakai platform.

\section{RESERCH CONTEXT}

LMSs usually gathered a range of users' performance $\log$ into database, such as login, forum posts and quiz grades. Since the limitation of different kinds of LMS, researchers have to dig more information from forum content, $\log$ files and survey etc.

Sakai has a core system that offers a basic set of learning tools along with the capacity to easily add or adapt new tools as they become available [16]. All of the tools share a common interface style and basic component. Since most of the tools are developed by different organizations, they usually have individual database design, which makes the behind-the-scenes view a more piecemeal and heterogeneous affair. Sakai also lacks members' interaction data collection tool until being equipped with a notification tool [21], called the Context-aware Activity Notification System (CANS), and it could be used to collect members' performance trace data and uses the concept of social context as a filter to deliver notifications to e-learners. Based on this tool, Laffey, Lin and Lin [22] exploited research works about social nature in Sakai.

In traditional classroom, instructors can understand members' social activities by observing. However, in an online course, data mining skills are necessary to analysis system log data. Data mining refers to computational techniques applied in order to uncover patterns in huge data sets, such as, website logs data, etc. The underling techniques draw on a wide range of algorithms and the variety of its investigations is also broad and ever increasing [16]. Educational data mining is an emerging field that exploits statistical, machine learning, and data mining algorithms over the different types of data in order to resolve educational research issues [23]. It is concerned with developing methods to better understand students and improve the setting where they learn [24]. It has been applied in different perspectives in education systems [25],

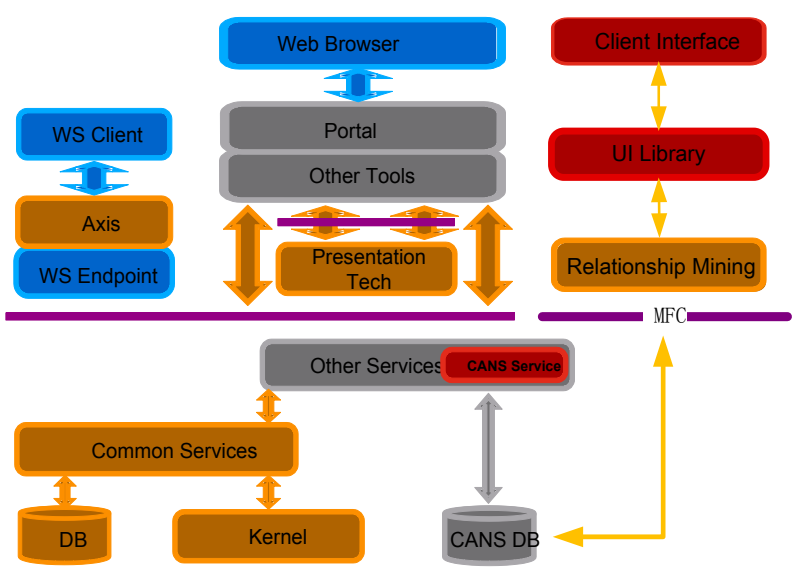

Figure 1. System architecture of Sakai and ReCa

such as student modeling, performance predicting, grouping students, and social network analysis [26]. It also can be oriented to different actors with each particular of view [27], such as students, educators, administrators [28].

While mining learning activities data in Sakai have certain obstacle for instructors and educators. Because data mining approach consumes a lot of manual work and requires database search skills. There is still no effective tool for instructors to find out participants' social relationship in online learning community. The main objective of ReCa design is to fill the gap by easily carrying out participants' social relationship matrix in Sakai platform.

\section{SySTEM DESIGN}

Sakai can offer a great variety of channels to facilitate resources sharing and communicating among members in a course. Members' information and performance, such as discussion, reading and writing, would be collected by CANS. This information is valuable for analyzing learning behavior and social relationship. But the step of data preparation usually consumes a lot of manual work, and lack of database operation skills is another obstacle for educators.

To solve the two obstacles, this study built a Relationship Calculation Tool ( $\mathrm{ReCa}$ ). $\mathrm{ReCa}$ aims to discover members' social relationship easily in online learning community based on Sakai platform.

The prerequisite of this research is that CANS was integrated in Sakai as a tool, and learners' all learning trace and collaborative behavior could be saved in CANS server database.

Cross-Industry Standard Process for Data Mining (CRISP-DM) provides a six step methodology of data mining project management, including business understanding, data understanding, data preparation, modeling, evaluation and deployment. CRISP-DM approach is not widely adopted by educators because of two reasons. Firstly, EDM practices require data mining technique skills and experiences. Secondly, in the process of EDM, data understanding and data preparation usually consume a lot of manual work, and also require researchers' database search skills. 


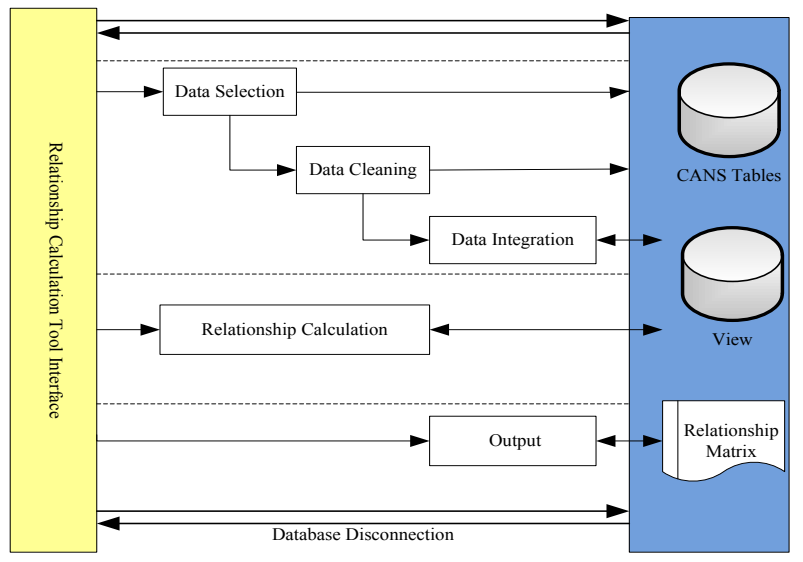

Figure 2. Mining process of Relationship Calculate Tool.

\section{A. Data Preparation}

First of all, ReCa would select data from CANS server database, and prepare for knowledge discovery. Data obtained from CANS database consist of several tables in which many of columns are useless for this research. In this process, $\mathrm{ReCa}$ relates tables with each other, selects valuable data, and integrates them into a new single view. The data used is mostly obtained members' action, subject, object, time, etc. Selected performance includes participation in discussion board, courseware content, and shared resources (See table 1).

\section{B. Modeling}

Once the data was prepared, social relationship mining modeling will be carried out in $\mathrm{ReCa}$ (See figure 3). Social relationship will be found by analyzing objects and members' performance. In case of discussion board, participants' activities will be recorded, such as posting a new thread, reading and replying others' thread, hence relationship could be revealed in these collaborative activities.

Instructors can select members' performance by the 'Relation Type' options, including discussion activities, wiki edit activities, learning content sharing activities, etc.

\section{Generate Relationship Matrix}

Social relationship matrix will be carried out based on calculation results (fig. 4). Participants' relationship could be showed, such as which participants responded to each other's, the facilitator's posts and how often they did so.

Netdraw will be needed if educators want to do more social network analysis work and data visualization.

\section{DISCUSSION}

In 2010 , the $\mathrm{ReCa}$ was used by online course instructional designers and instructors who used Sakai in East China Normal University. Many theoretical and empirical analyses emphasize the importance of collaboration among students in promoting the effectiveness of learning. The experts recognized the value of $\mathrm{ReCa}$, which is a way to assess and motivate learners' collaborative activity. The instructors indicated that traditionally they usually evaluated learners' collaborative actives by observing posts in discussion forum in online courses, but it is not accurate. $\mathrm{ReCa}$ can give them immediately a whole collaboration map of class and it really saves time and efforts. The experts also suggested that it would be better to develop a data visualization function in $\mathrm{ReCa}$ to make it easy to use for instructors.
TABLE I.

ACTION SELECTED FROM CANS DATABASE

\begin{tabular}{|l|c|c|c|}
\hline \multirow{2}{*}{\multicolumn{1}{|c|}{ Environment }} & \multicolumn{3}{|c|}{ Members' Action Selected } \\
\cline { 2 - 4 } & New & Read & Edit \\
\hline Discussion Board & $\sqrt{ }$ & $\sqrt{ }$ & NA \\
\hline Content & $\sqrt{ }$ & $\sqrt{ }$ & NA \\
\hline ChatRoom & $\sqrt{ }$ & NA & NA \\
\hline Wiki & NA & NA & $\sqrt{ }$ \\
\hline
\end{tabular}

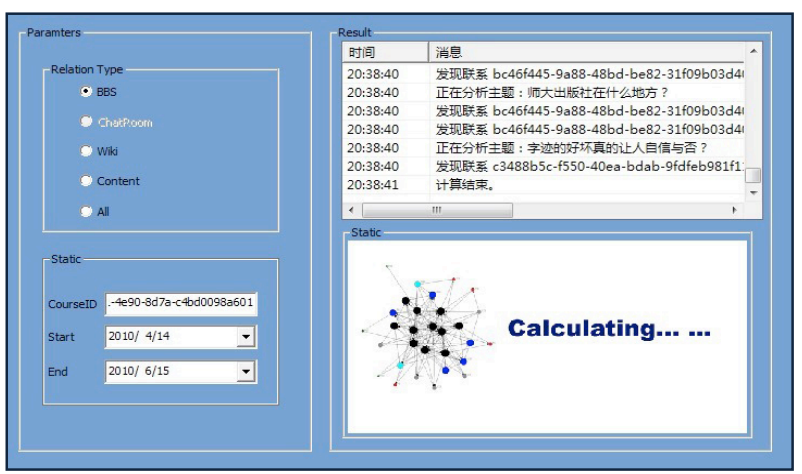

Figure 3. Interface of Relationship Calculate Tool.

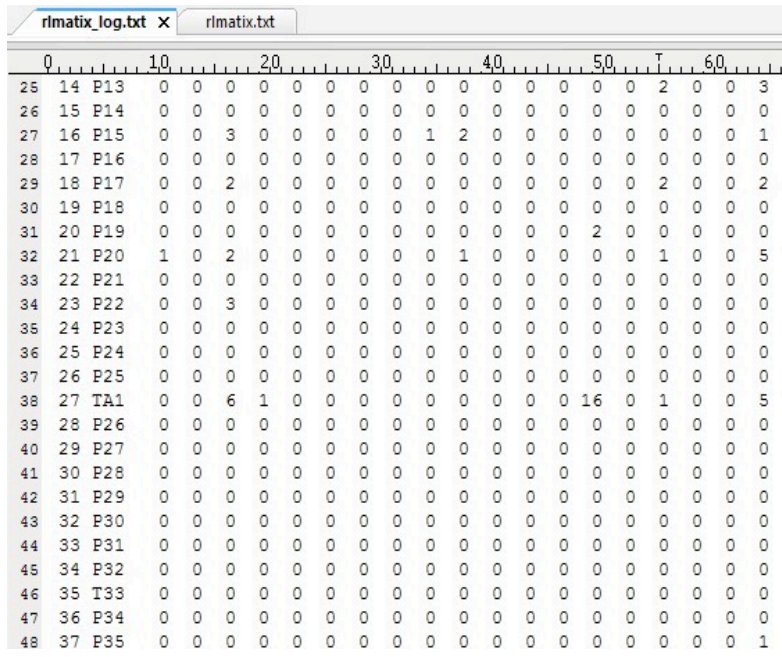

Figure 4. Social relationship matrix output

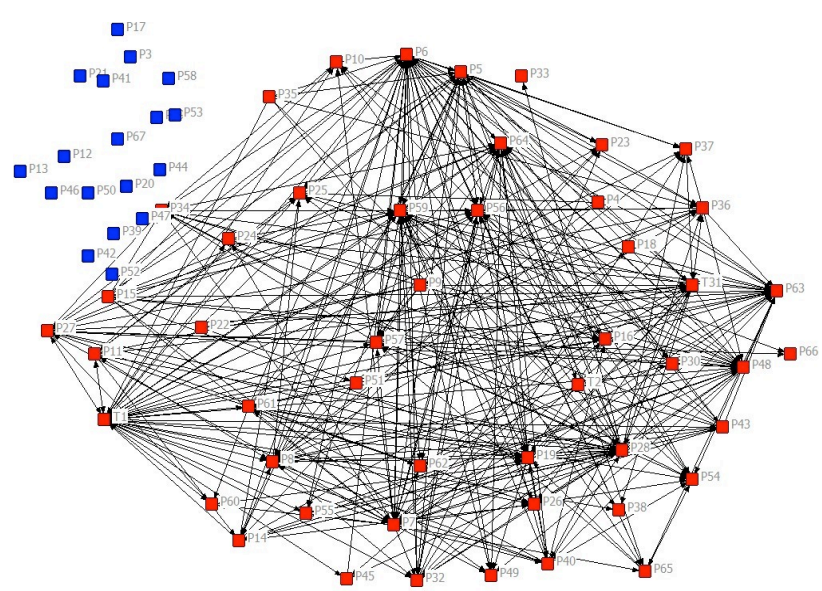

Figure 5. Social relationship visualization 


\section{CONCLUSION AND FUTURE WORK}

In this study, a social relationship calculation tool called $\mathrm{ReCa}$ was developed, in order to explore members' relationship easily in Sakai system. Currently, ReCa was designed only for the needs of members' relationship. Therefore, it will require modifications and extensions if it were used for different kinds of data, systems or problems. Our next work is to make $\mathrm{ReCa}$ available for more learning management platform, and integrating data visualization function. This study may help other LMSs' data mining tools' studies to be carried out in the future.

\section{REFERENCES}

[1] W.H. Rice, Moodle E-learning Course Development. A complete guide to succeful learning using Moodle. Packt publishing, 2006.

[2] J. Dewey, Democracy And Education. New York: Free Press, 1966.

[3] J. Piaget, Origins of Intelligence in Children. W W Norton \& Co (Sd), 1971.

[4] L. S. Vygotskiǐ and A. Kozulin, Thought and language. MIT Press, 1986

[5] F. Gabelnick, J. MacGregor, R. S. Matthews, and B. L. Smith, Learning Communities: Creating, Connections Among Students, Faculty, and Disciplines. Jossey-Bass, 1990.

[6] J. L. Laufgraben and N. S. Shapiro, Sustaining and Improving Learning Communities, 1st ed. Jossey-Bass, 2004.

[7] A. P. Rovai, "Sense of community, perceived cognitive learning, and persistence in asynchronous learning networks," The Internet and Higher Education, vol. 5, no. 4, 2002,pp. 319-332. http://dx.doi.org/10.1016/S1096-7516(02)00130-6

[8] E. Wenger, Communities of practice. Cambridge UK:: Cambridge University Press, 1998.

[9] M. P. Collins and Z. L. Berge, Computer Mediated Communication and the Online Classroom: Higher Education. Hampton Press, 1994.

[10] R. M. Palloff and K. Pratt, Building Learning Communities in Cyberspace: Effective Strategies for the Online Classroom, 1st ed. Jossey-Bass, 1999.

[11] E. W. Black, K. Dawson, and J. Priem, "Data for free: Using LMS activity logs to measure community in online courses," The Internet and Higher Education, vol. 11, no. 2, 2008,pp. 65-70. http://dx.doi.org/10.1016/j.iheduc.2008.03.002

[12] M. V. P. Cereijo, J. Young, and R. W. Wilhelm, "Factors facilitating student participation in asynchronous web-based course", Journal of Computing in Teacher Education, vol.18. 2001.

[13] A. P. Rovai and M. J. Wighting, "Feelings of alienation and community among higher education students in a virtual classroom," The Internet and Higher Education, vol. 8, no. 2, 2005, pp. 97-110, http://dx.doi.org/10.1016/j.iheduc.2005.03.001

[14] A. P. Rovai, "Development of an instrument to measure classroom community," The Internet and Higher Education, vol. 5, no. 3, 2002, pp. 197-211. http://dx.doi.org/10.1016/S1096-7516(02) 00102-1

[15] H. Cho, J. Lee, M. Stefanone, and G. Gay, "Development of computer-supported collaborative social networks in a distributed learning community," Behaviour \& Information Technology, vol. 24 , no. 6,2005 , p. 435. http://dx.doi.org/10.1080/0144929050 0044049

[16] O. G. McGrath, "Insights and surprises from usage patterns," in Proceedings of the 36th annual ACM SIGUCCS conference on User services conference - SIGUCCS '08, 2008,p. 59.

[17] Scott, John, Social network analysis: A handbook. London: Sage. 1991.

[18] Wasserman, Stanley, \& Faust, Katherine,. Social network analysis. Cambridge, MA: Cambridge University Press, 1994.

[19] Wellman, Barry. (1988). Structural analysis: From method and metaphor to theory and substance. In B. Welhnan \& S.D. Berkowitz (Eds.), Social structures: Anetwork approach.Cambridge: Cambridge University Press. 1998, pp. 19-61.

[20] C. Haythornthwaite, Social Network Analysis:An Approach and Technique for the Study of Information Exchange, Library \& Information Science Research, vol.18, no.4,1996, pp 323-342. http://dx.doi.org/10.1016/S0740-8188(96)90003-1

[21] C. Amelung, "Using Social Context and E-Learner Identity as a Framework for an E-Learning Notification System," International Journal on E-Learning, vol. 6, no. 4,2007, pp. 501-517.

[22] J. Laffey, G. Y. Lin, and Y. Lin, "Assessing Social Ability in Online Learning Environments," Journal of Interactive Learning Research, vol. 17, no. 2, 2006, pp. 163-177.

[23] T. Barnes, M. Desmarais, C. Romero, and S.Ventura, presented at the $2^{\text {nd }}$ Int. Conf. Educ. Data Mining, Cordoba, Spain,2009.

[24] R.Baker, "Data Mining for Education," in International Encyclopedia of Education, B. McGaw, P.Peterson, and E.Baker, Eds., $3^{\text {rd }}$ ed. Oxford, U.K.:Elsevier, 2010.

[25] C. Romero and S. Ventura, "Educational data mining: A survey from 1995 to 2005," Expert Systems with Applications, vol. 33, no. 1, 2007, pp. 135-146. http://dx.doi.org/10.1016/j.eswa.2006. $\underline{04.005}$

[26] C. Romero, S. Ventura,"Educational Data Mining: A Review of the Stat of the Art," IEEE Transactions on Systems, vol. 40, no. 6, 2010, pp.601-618.

[27] M. E. Zorrilla, E. Menasalvas, D. Marin, E. Mora, and J. Segovia, "Web usage mining project for improving web-based learning sites," in Web mining workshop, Cataluna, 2005.

[28] C. Romero, S. Ventura, and E. Garcia, "Data mining in course management systems: Moodle case study and tutorial," Comput. Educ., vol. 51, no. 1,2008, pp. 368-384. http://dx.doi.org/10.1016/ j.compedu.2007.05.016

\section{AUTHORS}

Niki Y. GUO, PhD from Department of Educational Technology at East China Normal University is an assistant professor in the College of Education at Zhejiang University. Research interests include educational data mining, social computing, and etc.

This research was supported by Zhejiang University independence research project "ZJU future classroom design and application model research". Received 17 April 2013. Published as resubmitted by the authors 02 June 2013. 